\title{
ANALISA PENINGKATAN KUALITAS CITRA BAWAH AIR BERBASIS KOREKSI GAMMA dan HISTOGRAM EQUALIZATION
}

\author{
Aria Hendrawan \\ Universitas Semarang \\ Semarang, Indonesia \\ Email: ariahendrawan@usm.ac.id
}

\author{
Pulung Nurtantio Andono \\ Universitas Dian Nuswantoro \\ Semarang, Indonesia \\ Email: pulung@ research.dinus.ac.id
}

\author{
Susanto \\ Universitas Semarang \\ Semarang, Indonesia \\ Email: susanto@usm.ac.id
}

\begin{abstract}
Citra air bawah laut memiliki kualitas yang gelap, hal ini tergantung dari tingkat kedalaman air pada waktu pengambilan citra atau gambar. Hasil citra yang memiliki kualitas yang kurang baik mempengaruhi hasil pencocokan pasangan citra bawah laut dengan algoritma SIFT. Penelitian ini bertujuan menggunakan metode image preprocessing Koreksi Gamma dan Histogram Equalization yang berfungsi untuk peningkatan kualitas citra bawah laut. Hasil penelitian ini menunjukkan peningkatan $27,76 \%$ menggunakan image preprocessing Koreksi Gamma dan Histogram Equalization dibandingkan tanpa peningkatan kualitas citra. Hasil uji t-test berpasangan memiliki hipotesa null ditolak sehingga terdapat perbedaan signifikan antara penerapan Koreksi Gamma disertai Histogram Equalization dan tanpa image enhancement.
\end{abstract}

Keywords-Koreksi Gamma, Histogram Equalization, Peningkatan Kualitas Citra, Image Preprocessing

\section{PENDAHULUAN}

Data terumbu karang di Indonesia mengalami kekurangan data. Data yang lengkap dan berkelanjutan sangat dibutuhkan untuk mengetahui kecenderungan yang terjadi pada ekosistem ini sehingga dapat dirumuskan satu bentuk pengelolaan yang terbaik untuk menjaga kelestariannya. [1]. Kemajuan pemetaan dasar laut di bidang robotika bawah air menjadi sebuah teknologi yang efektif untuk berbagai penerapan dari tersedianya warisan budaya situs arkeologi yang terendam terancam punah seperti terumbu karang yang disebabkan oleh berbagai sumber bahaya [2].

Hambatan yang terjadi pada penelitian citra bawah air adalah adanya penyerapan dan penyebaran cahaya di lingkungan bawah air. Kejadian tersebut merupakan akibat keterbatasan jarak pandang pengambilan citra oleh kamera [3]. Efek lain dari hal tersebut antara lain adalah hasil kualitas citra bawah air yang rusak [4]. Peningkatan kualitas citra pada dasarnya meningkatkan persepsi atau kemampuan menerjemahkan informasi gambar untuk manusia dan memberikan masukan "lebih baik" pada teknik pengolahan citra otomatis yang lain. Tujuan utama dari peningkatan citra adalah memodifikasi atribut gambar untuk membuatnya lebih cocok dalam menjalankan suatu tugas dan pengamatan yang lebih khusus. Faktor-faktor pengamatan yang lebih detil, seperti sistem pengamatan manusia dan pengalaman pengamat, akan memperkenalkan banyak subjektivitas ke pemilihan metode peningkatan citra. Ada banyak teknik yang dapat meningkatkan gambar digital tanpa merusak gambar [5].

Terdapat beberapa teknik perbaikan citra yaitu operasi titik, operasi spasial, operasi geometri dan operasi aritmatik. Operasi titik ini dilakukan dengan memodifikasi histogram citra masukan agar sesuai dengan karakteristik yang diharapkan. Histogram dari suatu citra adalah grafik yang menunjukkan distribusi frekuensi dari nilai intensitas piksel dalam citra tersebut. Salah satu metode dalam operasi titik, yaitu koreksi gamma (gamma correction) dan histogram equalization [6] Menurut penelitian Jonathan Cepeda-Negrete (2012) penggunaan koreksi gamma setelah algoritma color constanty untuk peningkatan citra gelap. Perbaikan citra ini dapat berguna dalam sejumlah computer vision dan tugas pengolahan citra [7].

Pada prinsipnya peningkatan kualitas citra merupakan pemrosesan citra dimana hasilnya lebih sesuai daripada citra asli yang diperuntukkan ke aplikasi yang akan digunakan [5].Sedangkan pada teknik pencocokan citra adalah aplikasi yang digunakan dalam pengolahan citra. Gambar direpresentasikan sebagai N-dimensi fitur vektor. Objek dari kelas yang sama memiliki fitur yang sama dan objek-objek yang berasal dari kelas yang berbeda memiliki fitur yang berbeda. Dalam proses pencocokan gambar, fitur digunakan untuk mendeteksi apakah gambar serupa atau tidak. Bahkan kita bisa menemukan apakah pola gambar adalah kelompok dari gambar asli atau tidak. Teknik pencocokan yang efisien harus mencari kesamaan atau ketidaksamaan dalam jangka waktu yang lebih rendah.

Banyak penelitian yang terus dikembangkan untuk mendapatkan teknik pencocokan yang optimal, misalnya algoritma SIFT [8]. Algoritma SIFT (Scale Invariant Feature Transform) diusulkan oleh Lowe merupakan sebuah pendekatan untuk mengeluarkan fitur invarian dari gambar. SIFT telah berhasil diterapkan untuk berbagai masalah dari computer vision berdasarkan fitur pencocokan termasuk pengenalan objek, estimasi posisi, pengambilan gambar dan banyak lainnya [21].

Pengolahan citra bawah air dapat digolongkan menjadi dua jenis, yaitu teknik gambar restorasi dan teknik peningkatan kualitas citra. Metode peningkatan kualitas citra cukup sederhana daripada teknik restorasi gambar [2]. Dalam teknik peningkatan kualitas citra, salah satu metode didalamnya yakni image preprocessing. Penelitian-penelitian sebelumnya yang dilakukan untuk preprocessing gambar peningkatan citra bawah air, diantaranya adalah S. Asadi Amiri (2012) menyajikan sebuah algoritma baru peningkatan citra, sederhana dan kuat untuk analisis gambar dengan mengubah nilai individu gamma piksel, hasilnya metoda yang diusulkan baik dalam meningkatkan kualitas gambar [17]. Sumathi C P dan G Gayathri Devi (2014) menyajikan pendekatan baru yang didasarkan pada koreksi Gamma dengan menentukan 
nilai gamma untuk meningkatkan rincian gambar. Hasil penelitian menunjukkan bahwa metoda yang diusulkan memiliki kinerja yang baik pada penggalian teks daerah dalam sebuah gambar [12]. Penelitian H. Hassanpour dan S. Asadi Amiri (2011) menyajikan metode baru peningkatan citra otomatis dengan mengubah nilai gamma piksel yang individu, hasilnya metoda yang diusulkan baik dalam meningkatkan kualitas gambar [15].

Penelitian-penelitian sebelumnya dalam penggunaan image preprocessing untuk pemanfaatan teknik pencocokan citra pada algoritma SIFT, diantaranya adalah penelitian Pulung Nurtantio (2013) yang mengusulkan penggunaan contrast stretching dan CLAHE (Contrast Limited Adaptive Histogram image Equalization) dengan Rayleigh scattering. Hasil penelitian tersebut adalah kesuksesan algoritma SIFT dalam meningkatkan pencocokan citra sampai $41 \%$, di mana nilai ini merupakan pengujian dari pencocokan citra melalui perbandingan teknik peningkatan citra contrast stretching dengan teknik CLAHE [6]. Penelitian selanjutnya Ricardus Anggi Pramunendar (2013) yang mengusulkan penggunaan HSV conversion image dengan auto level color correction. Hasil penelitian menunjukkan bahwa penggabungan 2 teknik peningkatan kualitas citra tersebut mampu meningkatkan pencocokan pasangan gambar sebanyak $4 \%$ [7].

Beberapa penelitian sebelumnya pernah dilakukan menunjukkan bahwa peningkatan teknik pencocokan gambar dengan SIFT mengalami peningkatan akurasi, namun tidak meningkatkan kualitas citra, hanya terfokus pada algoritma SIFT, seperti yang dilakukan oleh [23], [24], [25] [26], [27]. Menurut Anggi Pramunendar (2013) algoritma SIFT tergantung pada kualitas citra yang tujuannya untuk mengetahui pasangan keypoint yang cocok. Keberhasilan SIFT terbatas ketika mencoba pada kamera yang hasilnya diambil di bawah air [6]. Oleh karena itu, sebaiknya dilakukan prosesproses tambahan agar pendeteksian dan pencocokan keypoint dapat berjalan lebih baik [28].

\section{BAHAN DAN METODE PENELITIAN}

\subsection{Koreksi Gamma}

Banyak perangkat yang digunakan untuk merekam, mencetak atau menampilkan gambar pada umumnya menerapkan sebuah transformasi, disebut hukum daya, pada setiap piksel gambar yang memiliki efek nonlinier potensial listrik [10]:

$$
\mathrm{g}(\mathrm{u})
$$

$$
u^{\gamma}
$$

Dalam persamaan di atas u $\varepsilon[0,1]$ menunjukkan intensitas pixel gambar, $\gamma$ adalah sebuah konstanta positif yang memperkenalkan nilai gamma. Dengan asumsi, nilai $\gamma$ biasanya dapat ditentukan dengan penelitian, melalui kalibrasi dengan berbagai nilai-nilai potensial listrik yang diketahui melewati perangkat gambar. Jika $\gamma$ lebih besar dari 1 maka hasil keluarannya akan menjadi gelap. Sebaliknya, jika $\gamma$ lebih kecil dari 1 maka hasil keluarannya akan menjadi lebih terang. Dalam hal ini, penyesuaian dengan gamma dapat menjadi gagasan sebagai operasi penyesuaian kontras [22].

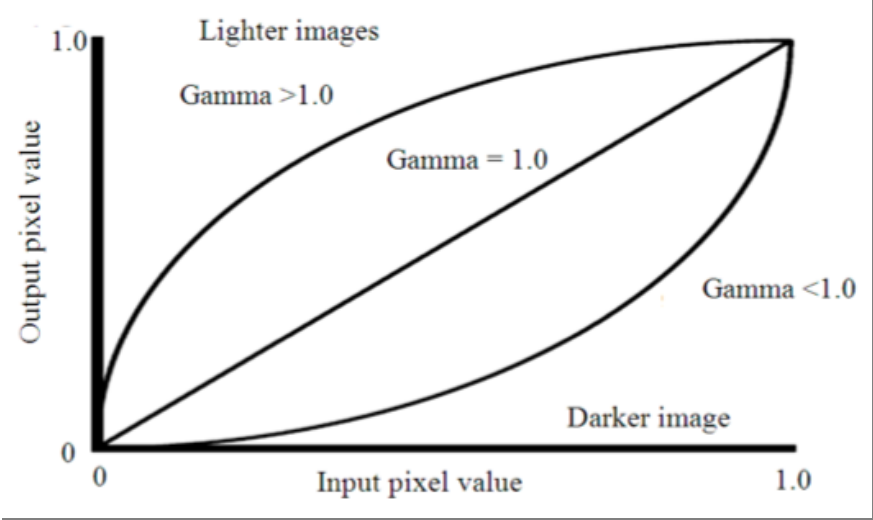

Gambar 1: Kurva Gamma [12].

\subsection{SIFT (Scale Invariant Feature Transform)}

Menurut Lowe (2009) SIFT terdiri dari empat tahap, yakni detection of scale-space extrema, keypoint localization, orientation assignment, dan keypoint descriptor [20]:

a. Detection of scale-space extrema

Tahap pertama dari deteksi keypoint adalah untuk mengidentifikasi lokasi dan perbandingan ukuran gambar yang ditetapkan secara berulang di bawah pandangan yang berbeda dari objek yang sama. Mendeteksi lokasi yang invariant untuk skala perubahan gambar dapat dicapai dengan mencari fiturfitur stabil di semua kemungkinan dari skala-skala menggunakan fungsi yang terus-menerus pada skala yang dikenal sebagai skala ruang. Di berbagai asumsi yang beralasan bahwa kemungkinannya kernel skalaruang adalah fungsi Gaussian. Oleh karena itu, Ruang skala gambar didefinisikan sebagai fungsi L $(\mathrm{x}, \mathrm{y}, \sigma)$ yang dihasilkan dari konvolusi dari skala variabel Gaussian $\mathrm{G}(\mathrm{x}, \mathrm{y}, \sigma)$ dengan gambar masukan I (x, y):
$\mathrm{L}(\mathrm{x}, \mathrm{y}, \sigma)$
y).$$
=\mathrm{G} \quad(\mathrm{x}, \mathrm{y}, \sigma) * \mathrm{I} \quad(\mathrm{x},
$$

Di mana * adalah operasi konvolusi pada $\mathrm{x}$ dan $\mathrm{y}$, dan:

$$
G(x, y, \sigma) \quad=\frac{1}{2 \pi \sigma^{2}} e^{-\left(x^{2}+\nu^{4} y ; z \sigma^{2}\right.}
$$

Untuk mendeteksi stabil lokasi keypoint pada skala ruang, [20] mengajukan untuk menggunakan scalespace extrema pada fungsi persamaan Gaussian dikonvolusikan dengan gambar, $\mathrm{D}(\mathrm{x}, \mathrm{y}, \sigma)$ yang dapat dikomputasikan dari perbedaan pada 2 skala yang sama dekat melalui sebuah konstanta faktor k:

$$
\begin{aligned}
\mathrm{D}(\mathrm{x}, \mathrm{y}, \sigma) & =(\mathrm{G}(\mathrm{x}, \mathrm{y}, \mathrm{k} \sigma)-\mathrm{G}(\mathrm{x}, \mathrm{y}, \sigma)) * \mathrm{I}(\mathrm{x}, \mathrm{y}) \\
& =\mathrm{L}(\mathrm{x}, \mathrm{y}, \mathrm{k} \sigma)-\mathrm{L}(\mathrm{x}, \mathrm{y}, \sigma) \ldots \ldots \ldots \ldots(4)
\end{aligned}
$$

b. Keypoint Localization 
Setelah calon keypoint telah ditemukan dengan membandingkan sebuah pixel ke pixel terdekat, langkah berikutnya adalah untuk melakukan rincian yang sesuai pada data terdekat untuk lokasi, skala dan rasio kurva. Informasi ini memungkinkan poin ditolak yang mempunyai rendah kontras (dan karenanya sensitif terhadap noise) atau lokasi yang buruk sepanjang tepi. Implementasi awal pendekatan keypoint terletak di lokasi dan skala dari titik tengah sampel. Pendekatannya menggunakan perluasan Taylor (hingga kuadrat) pada fungsi skala-ruang D (x, $\mathrm{y}, \sigma)$, digeser sehingga yang asli merupakan titik sampel poin:

$D(x) \quad D \perp \frac{v g r}{i x} x+\frac{1}{3} x^{\top} \frac{v^{2} 0}{d x^{2}} x$

Di mana D dan turunannya di evaluasi pada sampel point dan $\mathrm{x}=(\mathrm{x}, \mathrm{y}, \sigma) \mathrm{T}$ adalah offset dari titik ini. Lokasi ekstrem, x', ditentukan dengan mengambil turunan dari fungsi ini sehubungan dengan $\mathrm{x}$ dan pengaturan nol, memberikan

$$
y^{\prime} \quad \frac{12 \overline{\mathrm{D}}-x}{v x} \frac{i \mathrm{D}}{\mathrm{v} x}
$$

c. Orientation Assignment

Dengan menetapkan orientasi yang konsisten untuk setiap keypoint berdasarkan sifat lokal gambar, Deskripsi keypoint dapat diwakili terhadap orientasi ini karena itu mencapai variasi untuk rotasi gambar. Mengikuti penelitian dengan sejumlah pendekatan untuk menetapkan orientasi local, telah ditemukan untuk memberikan hasil yang paling stabil. Skala keypoint digunakan untuk memilih gambar Gaussian yang baik, L, dengan skala terdekat, sehingga semua komputasi dilakukan dengan cara skala invariant. Untuk setiap sampel gambar, L(x,y), pada skala ini, besarnya gradient yang ditunjukkan $\mathrm{m}(\mathrm{x}, \mathrm{y})$ dan orientasi, $\theta(\mathrm{x}, \mathrm{y})$ adalah sebelum dikomputasi menggunakan persamaan pixel

$n(x, y)$

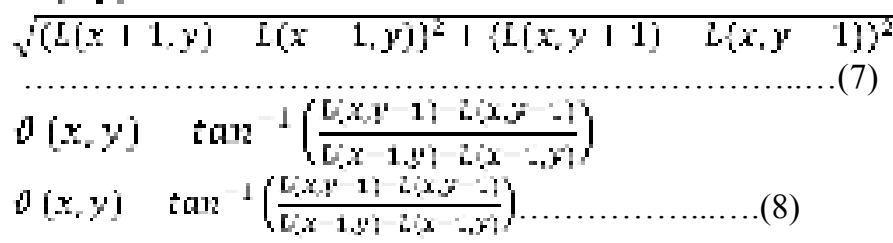

d. Keypoint Descriptor

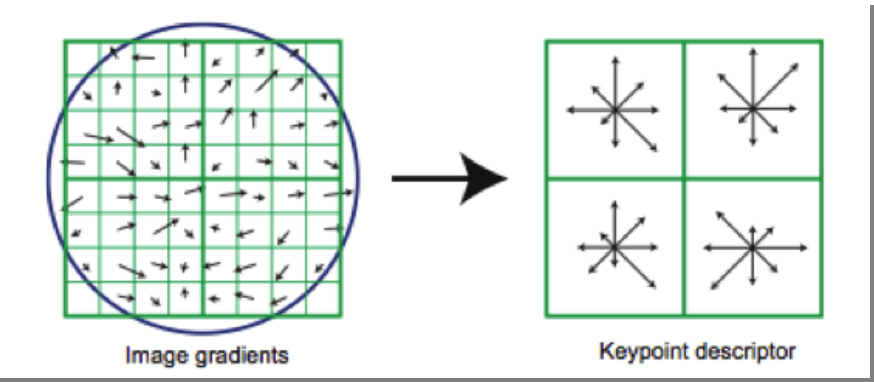

Gambar 2: Komputasi Keypoint Descriptor

Gambar pertama di atas merupakan besarnya gradien dan orientasi sampel di sekitar lokasi keypoint, menggunakan skala keypoint untuk memilih tingkat Gaussian untuk gambar yang tidak jelas. Untuk mencapai orientasi invariance, koordinat dan deskripsi orientasi gradien diputar terhadap orientasi keypoint.

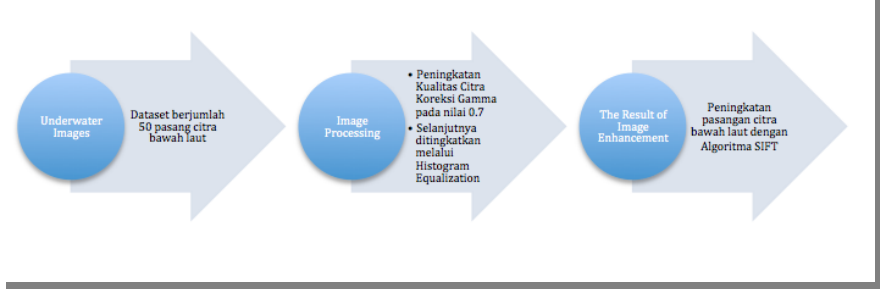

Gambar 3: Proses Pencocokan Pasang Gambar

\section{HASIL PENELITIAN}

Dari hasil peningkatan kualitas citra bawah laut dengan Koreksi Gamma memiliki rentang nilai terbaik yakni pada nilai gamma 0.7 [31]. Pada Penelitian ini hasil Koreksi Gamma disertai dengan Histogram Equalization tampak seperti gambar 4

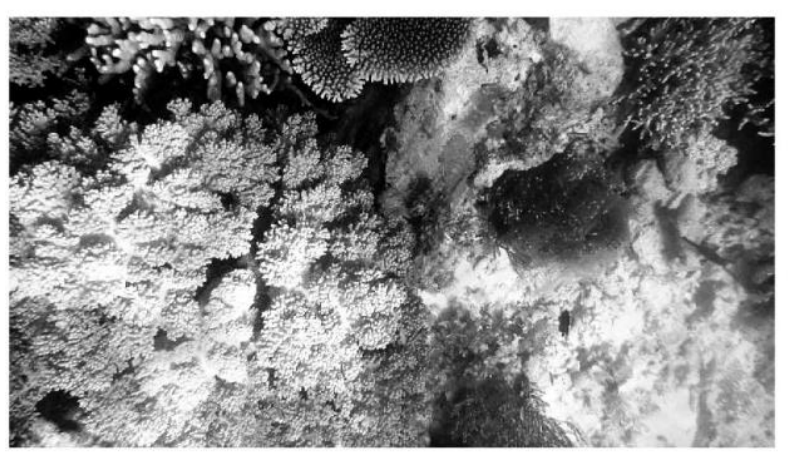


Gambar 4: Citra Bawah Laut dengan Koreksi Gamma dan Histogram Equalization

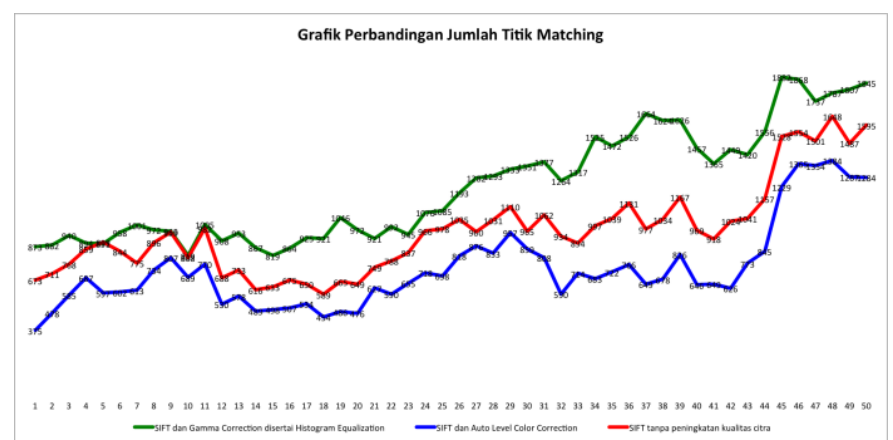

Gambar 5: Grafik Hasil Titik Pencocokan Citra Bawah laut dengan Koreksi Gamma dan Histogram Equalization

Dari 50 buah tersebut diuji dengan algoritma SIFT tanpa peningkatan kualitas citra, jumlah rata-rata titik pencocokan gambarnya didapatkan hanya 962,96 titik. Dari nilai koreksi gamma mulai 0,1 s.d. 1.0 ternyata jumlah rata-rata titik pencocokan gambar yang paling banyak adalah nilai koreksi gamma 0,7 dan Histogram Equalization dengan jumlah titik 1230. Ditunjukkan pada gambar 5 di atas. Melihat grafik kolom di atas maka didapatkan peningkatan dari penggunaan metode processing koreksi gamma dan Histogram Equalization pada algoritma SIFT sebesar $27,76 \%$ yang diperoleh dari rumus di bawah ini:

$$
\text { Banyaknya peningkatan }=\frac{\chi_{b} Y_{u}}{\chi_{u}} .
$$

Dimana $\gamma_{a}$ adalah jumlah rata-rata titik pencocokan gambar tanpa peningkatan kualitas citra, sedangkan $\gamma_{i}$ adalah jumla rata-rata titik pencocokan gambar dengan koreksi gamma dan HE.

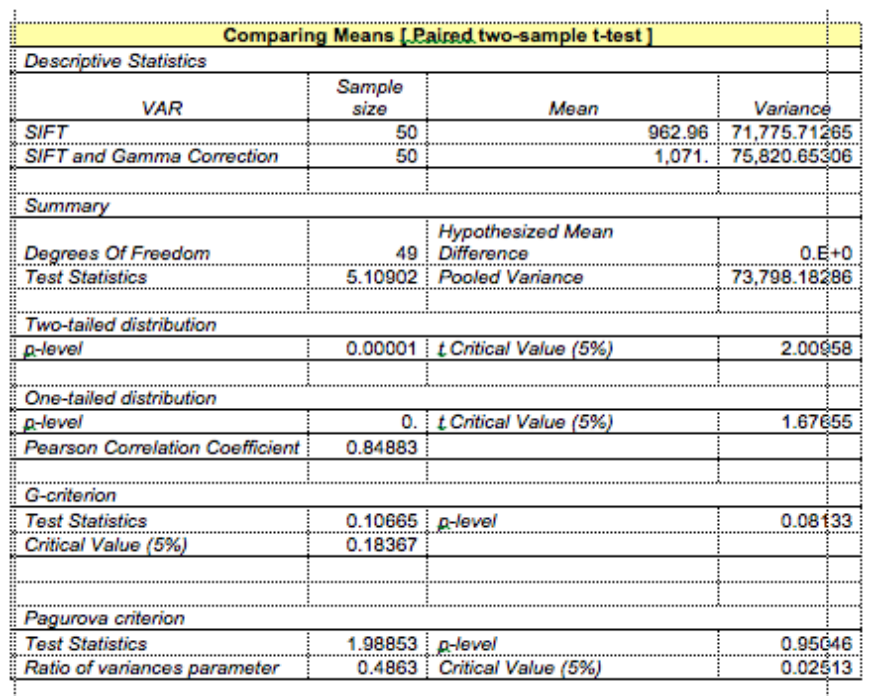

Gambar 6: Hasil Uji T-Test Berpasangan
Pada hasil gambar 6 di atas menunjukkan bahwa hasil dari hypothesized mean difference nya adalah null. Hal ini mengandung makna di mana terdapat perbedaan yang signifikan antara 2 sampel yang telah di uji yaitu SIFT tanpa peningkatan kualitas citra dengan SIFT - Koreksi gamma dan Histogram Equalization

\section{KESIMPULAN}

Peningkatan kualitas citra bawah laut dengan Koreksi Gamma dan Histogram Equalization mendapatkan hasil terbaik yakni terdapat rata-rata 1230 titik untuk pencocokan pasangan citra melalui algoritma SIFT disertai Koreksi Gamma dan Histogram Equalization. Hasil SIFT pencocokan pasangan citra bawah laut dengan menggunakan Koreksi gamma dan HE meningkat $27,76 \%$ dari pencocokan pasangan citra tanpa peningkatan kualitas citra bawah laut.

\section{REFERENCES}

[1] Abdullah Habibi, Naneng Setiasih, and Jensi Sartin, A Decade of Reef Check Monitoring: Indonesian Coral Reefs, Condition and Trends.: The Indonesian Reef Check Network, 2007.

[2] K. Iqbal, R. A. Salam, A. Osman, and A. Z. Talib, "Underwater Image Enhancement Using an Integrated Colour Model," IAENG International Journal of Computer Science, Vol. 34, No. 2, 2007.

[3] C Beall, B J Lawrence, V Ila, and F Dellaert, "Reconstruction 3D Underwater Structures", Atlantic, 2010.

[4] Faraj Alhwarin, Chao Wang, Danijela Ristić- Durrant, and Axel Gräser, "Improved SIFT- features matching for object recognition," in VoCS'08 Proceedings of the 2008 international conference on Visions of Computer Science: BCS International Academic Conference, 2008, pp. 179-190.

[5] J Floor Anthoni. (2005) [Online]. http://www.seafriends.org.nz/phgrap h/water.htm

[6] Pulung Nurtantio Andono, "Underwater Image Enhancement Using Adaptive Filtering For Enhanced SIFT-Based Image Matching”, Journal of Theoretical and Applied Information Technology Vol.51 No. 3, 2013.

[7] Anggi Pramunendar, R, "Auto Level Color Correction for Underwater Image Matching Optimization", IJCSNS International Journal of Computer Science and Network Security, Vol.13, No.1, January 2013.

[8] Raman Maini, "A Comprehensive Review of Image Enhancement Techniques", Journal of Computing Vol. 2, 2010.

[9] Dr. Ekta Walia, "A Conceptual Study on Image Matching Techniques", Globall Journal of Computer Science and Technology, 2010.

[10] R.C. Gonzalez, R.E. Woods, "Digital Image Processing”, Prentice Hall, Upper Saddle River, NJ 07458, 2002.

[11] Darma Putra, "Pengolahan Citra Digital", Penerbit Andi, 2010.

[12] Sumathi C P and G Gayathri Devi, "Automatic Text Extraction From Complex Colored Images Using Gamma Correction Method”, Journal of Computer Science 10 (4):705-715, 2014

[13] S. Asadi Amiri, H. Hassanpour, A.K. Pouyan, "Texture Based Image Enhancement Using Gamma Correction", Middle-East Journal of Scientific Research, Vol. 6, pp. 569-574. 2010.

[14] M. Farshbaf Doustar, H. Hassanpour, "A Locally-Adaptive Approach For Image Gamma Correction", Proc. Signal Processing and their Applications (ISSPA), pp. 73- 76, 2010.

[15] H. Hassanpour dan S. Asadi Amiri, "Image Quality Enhancement Using Pixel-Wise Gamma Correction Via SVM Classifier", University of Shahrood Technology, 2011.

[16] Yeong-Kang Lai, "Dynamic Gamma-Correction Algorithm for Improving Color LCD Systems”, IEEE, 2011. 
[17] S. Asadi Amiri, "A Preprocessing Approach for Image Analysis Using Gamma Correction", Department of Computer Engineering Shahrood University of Technology Iran, 2012.

[18] Raimondo Schettini and Silvia Corchs, "Underwater Image Processing: State of The Art of Restoration and Image Enhancement Methods", Hindawi Publishing Corporation EURASIP Journal on Advances in Signal Processing, 2010.

[19] S. Lee, "Content-based image enhancement in the compressed domain based on multi-scale $\alpha$-rooting algorithm", Pattern Recognition Letters, Vol. 27, pp. 1054-1066, 2006.

[20] David G Lowe, "Distinctive Image Featuresfrom Scale-Invariant Keypoints," International Journal of Computer Vision, 2004.

[21] Huibin Wang, Hongye Sun, Jie Shen, and Zhe Chen, "A Research on Stereo Matching Algorithm for Underwater Image," in International Congress on Image and Signal Processing, 2011.

[22] Jakkarin Singnoo, Graham D. Finlayson, "Understanding the Gamma Adjustment of Images", School of Computing Sciences, University of East Anglia, Norwich, UK, 2014.

[23] Y. Bastanlar, A. Temizel, and Y. Yardmc, "Improved SIFT matching for image pairs with scale difference," IET Electronic Letters, vol. vol 46, no. 5, pp. 346-348, 2012.

[24] Offir Pele and Michael Werman, "A Linear Time Histogram Metric for Improved SIFT Matching," in ECCV '08 Proceedings of the 10th European Conference on Computer Vision: Part III, 2008, pp. 495-508.
[25] Plinio Moreno, Alexandre Bernardino, and José Santos Victor, "Improving the SIFT descriptor with smooth derivative filters," Pattern Recognition Letters, vol. Volume 30, no. 1, pp. 18-26, 2009.

[26] Daw Tung Lin and Chin Hui Hsu, "Improving the Efficiency and Accuracy of SIFT Image Matching," Computer Applications and Computational Science, vol. 145, p. 227 233, 2012.

[27] Faraj Alhwarin, Chao Wang, Danijela Ristić-Durrant, and Axel Gräser, "Improved SIFT-features matching for object recognition," in VoCS'08 Proceedings of the 2008 international conference on Visions of Computer Science: BCS International Academic Conference, 2008, pp. 179- 190.

[28] Rommy Rakhman Arief, “Analisis Penggunaan Scale Invariant Feature Transform Sebagai Metode Ekstraksi Fitur Pada Pengenalan Jenis Kendaraan", Universitas Indonesia, 2010.

[29] Jonathan Cepeda-Negrete and Raul E. Sanchez-Yanez, "Combining Color Constancy and Gamma Correction for Image Enhancement”, IEEE, 2012.

[30] K. Somasundaram and P. Kalavathi, "Medical Image Contrast Enhancement based on Gamma Correction", Department of Computer Science and Applications Gandhigram Rural Institute, 2011.

[31] Hendrawan, Aria; and Nurtantio Andono, Pulung "Analisis Peningkatan Kualitas Citra Bawah Air Berbasis Koreksi Gamma Untuk Pencocokan Gambar Pada Algoritma SIFT”. Jurnal Tr@nsformatika, 2014. 